\title{
CT-Derived Pulmonary Artery Diameters to Preselect for Echocardiography in COPD Patients Eligible for Bronchoscopic Treatments
}

\author{
Marieke C. van der Molen ${ }^{\text {a }}$ Jorine E. Hartman ${ }^{\text {a }}$ Karin Klooster ${ }^{\mathrm{a}}$ \\ Huib A.M. Kerstjens ${ }^{a}$ Joost van Melle ${ }^{b}$ Tineke P. Willems ${ }^{c}$ Dirk-Jan Slebos ${ }^{a}$ \\ aDepartment of Pulmonary Diseases, University of Groningen, University Medical Center Groningen, Groningen, \\ The Netherlands; ${ }^{b}$ Department of Cardiology, University of Groningen, University Medical Center Groningen, \\ Groningen, The Netherlands; ${ }^{C}$ Department of Radiology, University of Groningen, University Medical Center \\ Groningen, Groningen, The Netherlands
}

\section{Keywords}

Interventional pulmonology · COPD · Emphysema ·

Pulmonary hypertension · Computed tomography

\begin{abstract}
Background: Currently, patients with COPD who are evaluated for bronchoscopic treatments are routinely screened for pulmonary hypertension (PH) and systolic left ventricle dysfunction by echocardiography. Objectives: We evaluated the prevalence of $\mathrm{PH}$ and systolic left ventricle dysfunction in this patient group and investigated if the previously proposed CT-derived pulmonary artery to aorta (PA:A) ratio $>1$ and PA diameter measurements can be used as alternative screening tools for $\mathrm{PH}$. Methods: Two hundred fifty-five patients were included in this retrospective analysis ( $\mathrm{FEV}_{1}$ 25\%pred, RV 237\%pred). All patients received transthoracic echocardiography and chest CT scans on which diameters of the aorta and pulmonary artery were measured at the bifurcation and proximal to the bifurcation. Results: Following echocardiography, 3 patients (1.2\%) had $\mathrm{PH}$ and $1(0.4 \%)$ had systolic left ventricle dysfunction. Using a PA:A ratio $>1$, only $10.3 \%$ of the patients with a right ventricular systolic pressure (RVSP) $\geq 35 \mathrm{~mm} \mathrm{Hg}$ were detected and none of the pa-
\end{abstract}

karger@karger.com www.karger.com/res

Karger $\stackrel{\text { ' }}{=}$

BOPEN ACCESS
(C) 2020 The Author(s)

Published by S. Karger AG, Basel

This article is licensed under the Creative Commons AttributionNonCommercial-NoDerivatives 4.0 International License (CC BY NC-ND) (http://www.karger.com/Services/OpenAccessLicense). Usage and distribution for commercial purposes as well as any distribution of modified material requires written permission. tients with an RVSP $>50 \mathrm{~mm}$ Hg were detected. Patients with an RVSP $\geq 35 \mathrm{~mm} \mathrm{Hg}$ had significantly higher PA diameters ( 29.5 vs. $27.5 \mathrm{~mm} ; p=0.02$ ) but no significantly different PA:A ratios. All patients with an RVSP $>50 \mathrm{~mm} \mathrm{Hg}$ had PA diameters $>30 \mathrm{~mm}$. Conclusions: The prevalence of $\mathrm{PH}$ and systolic left ventricle dysfunction is low in this preselected cohort of patients with severe COPD. In this population, a PA:A ratio $>1$ is not a useful cardiac screening tool for PH. A PA diameter $>30 \mathrm{~mm}$ could substitute for routinely performed echocardiography in the screening for $\mathrm{PH}$ in this patient group.

(C) 2020 The Author(s)

Published by S. Karger AG, Basel

\section{Introduction}

An emerging subgroup of patients with severe COPD may benefit from bronchoscopic treatment modalities [1]. Currently, all patients that are considered eligible for a bronchoscopic treatment are routinely screened for pulmonary hypertension $(\mathrm{PH})$ and systolic left ventricle dysfunction by echocardiography $[2,3]$ since cardiac comorbidities are frequently present in patients with COPD and severe $\mathrm{PH}$ and systolic left ventricle dysfunction are 
Fig. 1. CT-derived measurements of the PA. I Diameters of the PA and A to calculate the PA:A ratio in the axial view, II Perpendicular diameters of the PA. PA:A, pulmonary artery to aorta; A, aorta; PA, pulmonary artery.

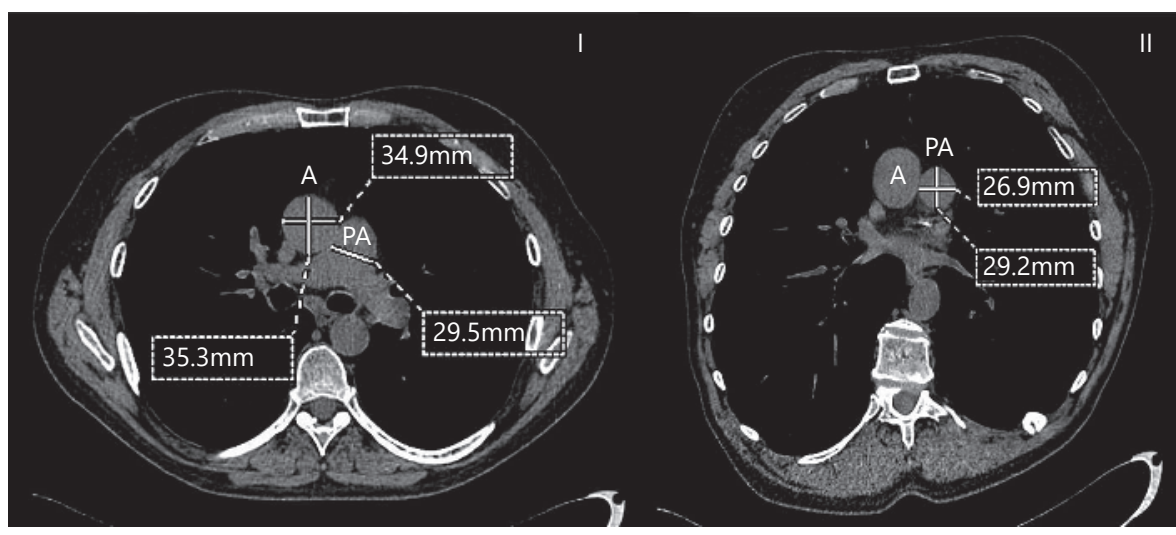

known to increase per procedural risks [4]. Therefore, according to current recommendations, a right ventricle systolic pressure (RVSP) $>50 \mathrm{~mm} \mathrm{Hg}$ and left ventricular ejection fraction (LVEF) $<45 \%$ disqualify patients for bronchoscopic treatments $[2,3]$.

Notwithstanding the importance of adequate cardiac screening, echocardiography is a cumbersome process since hyperinflation is known to impede cardiac imaging due to the lack of adequate acoustic windows. RVSP measurements are, therefore, often difficult to perform in patients with severe COPD $[5,6]$. Moreover, severe $\mathrm{PH}$ and systolic left ventricle dysfunction are present in only a small number of patients with severe COPD [7-9]. This prompted the evaluation of noninvasive alternatives for echocardiography in the screening of patients for $\mathrm{PH}$. Computed tomography (CT)-derived pulmonary artery (PA) diameter measurements and a pulmonary artery to aorta (PA:A) ratio $>1$ have been proposed as alternative screening tools for $\mathrm{PH}$, but studies in patients with severe COPD are scarce $[10,11]$.

In this study, we aimed to investigate 2 research questions. First, we addressed the prevalence of $\mathrm{PH}$ and systolic left ventricle dysfunction based on echocardiographic findings in this specific patient group. Second, we investigated the feasibility of using CT-derived PA:A ratios and PA diameters and whether these measurements could be a valid alternative for echocardiography in this patient group.

\section{Materials and Methods}

\section{Study Population}

Baseline data of all patients with severe COPD who were screened for bronchoscopic treatments in the University Medical Center Groningen and underwent echocardiography as part of the screening program were included in the database. Patients were excluded if an underlying cardiac genetic disease was present or if echocardiography was performed $>2$ years prior to the screening program. Written informed consent was obtained from all participants for the use of their data. According to the local ethics committee, this study did not fall within the scope of the WMO (Dutch Medical Research with Human Subjects Law) and therefore no formal approval was needed.

\section{Echocardiography}

Cardiac function was evaluated using transthoracic echocardiography. Patients received standard 2D and Doppler echocardiography in either the UMCG or the referring hospital. The following variables were assessed according to prevailing guidelines of the European Society of Cardiology: systolic left ventricular function using the Simpson method, left ventricle end diastolic diameter, peak velocity of the early E-wave and atrial A-wave and the E/A ratio, early diastolic mitral annular velocity $\left(\mathrm{E}^{\prime}\right)$ and the $\mathrm{E} / \mathrm{E}^{\prime}$ ratio, tricuspid annular plane systolic excursion, inferior caval vein diameter on inspiration and expiration, and RVSP.

\section{CT-Derived PA Measurements}

All patients underwent CT of the chest as part of the screening program. In all patients, CT of the chest was performed in the University Medical Center Groningen according to standard protocols. First author performed the measurements on all CT scans using TeraRecon AquariusNET iNtuition Software version 4.4.13. P4 (TeraRecon, Foster City, CA, USA). Two methods were earlier described to measure the PA diameter, and both measurements were performed on all CT scans. First, the main PA and A diameters were measured at the level of the PA bifurcation in the axial view. For the A diameters, 2 perpendicular measurements were taken and averaged which conform to the technique that was previously described (Fig. 1-I) [10]. Second, perpendicular PA diameters were measured proximal to the PA bifurcation which conform to the earlier description (Fig. 1-II) [12]. To assess interobserver variation, a second blinded reviewer (TW, radiologist) measured the diameters.

\section{Statistical Analysis}

Spearman correlations were calculated to determine the relationship between RVSP, PA:A ratio, and PA diameters. An independent $t$ test was performed to measure the difference in RVSP between the PA:A $\leq 1$ and $\mathrm{PA}: \mathrm{A}>1$ groups since a $\mathrm{PA}: \mathrm{A}>1$ showed 


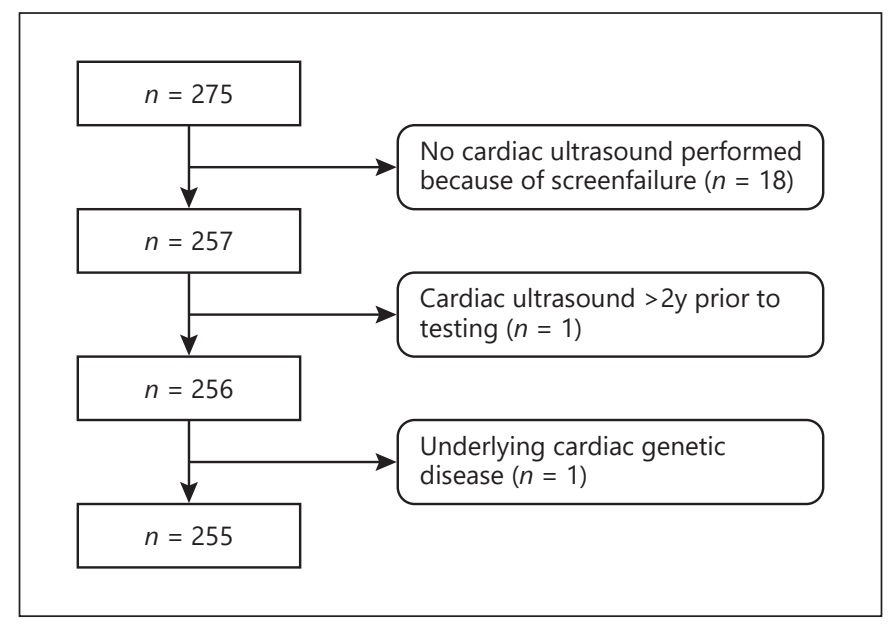

Fig. 2. Flow diagram of patients in whom echocardiography data were used.

the highest sensitivity and specificity in detecting $\mathrm{PH}$ in patients with COPD [10]. An independent $t$ test was performed to measure the difference in PA:A ratio, $\mathrm{A}$ and $\mathrm{PA}$ diameters between the $\mathrm{RVSP}<35$ and $\geq 35 \mathrm{~mm} \mathrm{Hg}$ groups since $\mathrm{PH}$ is considered unlikely in patients with an RVSP $\leq 35 \mathrm{~mm} \mathrm{Hg}$ [13]. Receiver operating characteristic analysis was performed to assess discriminatory power of CT-derived PA diameters and the PA:A ratio in predicting the presence of RVSP $>35 \mathrm{~mm} \mathrm{Hg}$. Intraclass correlation coefficients were calculated to measure interobserver agreement of CT-derived PA measurements. A multiple linear regression model was performed to test for independent predictors of the RVSP. Data analyses were performed using IBM SPSS statistics (IBM SPSS version 23; IBM, New York, NY, USA) and $p$ values of $<0.05$ were considered to be statistically significant.

\section{Results}

Between 2014 and 2018,275 patients were screened for bronchoscopic treatments. Useable echocardiography data were obtained in 255 patients (Fig. 2). Patient characteristics are shown in Table 1.

\section{Prevalence of Patients with $\mathrm{PH}$ and/or $\mathrm{CHF}$}

Of the 255 patients who received echocardiography, 3 patients had an RVSP $>50 \mathrm{~mm} \mathrm{Hg}(51,63$, and $67 \mathrm{~mm} \mathrm{Hg}$, respectively) and 1 patient had an LVEF $<45 \%$. An expansion of the numbers of deviating echocardiographic measurements is shown in Table 2.

\section{Feasibility of Echocardiographic Measurements}

In 169 of 255 patients (66.3\%), RVSP measurements could not be performed due to the absence of tricuspid
Table 1. Patient characteristics

\begin{tabular}{lcr}
\hline & Median (range) & $N$ \\
\hline Demography & & \\
Age, years & $61.0(39-78)$ & 255 \\
Men, $n$ (\%) & $79(31.0)$ & 255 \\
Pack-years of smoking & $39.5(8-148)$ & 254 \\
BMI, kg/m ${ }^{2}$ & $23.2(15.8-36.5)$ & 255 \\
Lung function & & \\
FEV, \%pred & $25.4(11.9-48.8)$ & 255 \\
RV, \% pred & $237(109-484)$ & 254 \\
DLCO, \%pred & $29.4(12.4-75.9)$ & 179 \\
Cardiac function & & \\
LVIDd, mm & $42(29-57)$ & 216 \\
TAPSE, mm & $19.7(10.3-34.1)$ & 216 \\
MV E/A ratio & $0.84(0.5-1.9)$ & 123 \\
E/e' ratio & $7.3(4.2-16.0)$ & 91 \\
IVC exp, mm & $15.0(6.8-25.3)$ & 110 \\
RVSP, mm Hg & $33(14-67)$ & 86 \\
CT-derived PA measurements & & \\
PA:A ratio & $0.82(0.5-1.1)$ & 254 \\
A diameter, mm & $33.7(23.2-47.4)$ & 254 \\
PA diameter, mm & $27.3(18.9-41.0)$ & 254 \\
PA diameter (pend), mm & $27.6(18.7-40.5)$ & 254 \\
\hline
\end{tabular}

Data are presented as median (range) or $n(\%) . \mathrm{FEV}_{1}$, forced expiratory volume in 1 second; RV, residual volume; DLCO, diffusing capacity of the lung for carbon monoxide; IC/TLC, inspiratory to total lung capacity; LVIDd, left ventricular internal dimension diastole; TAPSE, tricuspid annular plane systolic excursion; MV E/A, peak late to early mitral inflow velocity; E/e', peak early mitral inflow to peak early diastolic mitral annular velocity; IVC exp, diameter of the inferior caval vein on expiration; RVSP, right ventricular systolic pressure; CT, computed tomography; PA:A ratio, pulmonary artery-to-aorta ratio; A, aorta; PA, pulmonary artery.

regurgitation or poor acoustic window. For the same reason, LVEF could not be measured in 14 of 255 patients (5.5\%). An expansion of the numbers of obtained echocardiographic measurements is shown in Table 2.

\section{RVSP and CT-Derived PA Measurements}

PA:A Ratio

PA:A ratio was not significantly associated with RVSP (rho $=0.21 ; p=0.06$ ). There was no significant difference in RVSP between the PA:A $\leq 1$ and PA:A $>1$ groups (33.3 and $32.8 \mathrm{~mm} \mathrm{Hg}$, respectively; $p=0.87$ ). Alternatively, there was no significant difference in the PA:A ratio between the RVSP $<35 \mathrm{~mm} \mathrm{Hg}$ and RVSP $\geq 35 \mathrm{~mm} \mathrm{Hg}$ groups (0.86 and 0.82 , respectively; $p=0.14$ ). Using a PA:A ratio $>1$, only 4 of the 39 patients with an RVSP $\geq 35$ $\mathrm{mm} \mathrm{Hg}$ were detected, and none of the patients with an 
Table 2. Number of patients with deviating echocardiographic measurements

\begin{tabular}{lcl}
\hline & $N(\%)$ & $\begin{array}{l}\text { Valid } \\
\text { measurements, } n(\%)\end{array}$ \\
\hline LVEF $<45 \%$ & $1(0.4)$ & $241(94.5)$ \\
RVSP $\geq 35 \mathrm{~mm} \mathrm{Hg}$ & $39(15.3)$ & $86(33.7)$ \\
RVSP $>50 \mathrm{~mm} \mathrm{Hg}$ & $3(1.2)$ & $86(33.7)$ \\
IVC $>21 \mathrm{~mm}$ & $8(3.1)$ & $110(43.1)$ \\
IVC collaps $<50 \%$ & $7(2.7)$ & $103(40.4)$ \\
LVIDd $<-2$ SD & $51(20.0)$ & $216(84.7)$ \\
TAPSE $<17$ mm & $32(12.5)$ & $216(84.7)$ \\
MV E/A ratio $<0.8$ & $40(15.7)$ & $123(48.2)$ \\
E/e' ratio $>6.0$ & $75(29.4)$ & $91(35.7)$ \\
\hline
\end{tabular}

Data are presented as number of patients with deviating measurements, total number of patients with this measurement, and percentage of the number of patients who received echocardiography. LVEF, left ventricular ejection fraction; RVSP, right ventricular systolic pressure; IVC, inferior caval vein; LVIDd, left ventricular internal dimension diastole; TAPSE, tricuspid annular plane systolic excursion; MV E/A, peak late to early mitral inflow velocity; E/e', peak early mitral inflow to peak early diastolic mitral annular velocity.

RVSP $>50 \mathrm{~mm} \mathrm{Hg}$ (Table 3). Receiver operating characteristic analysis was performed and the area under the curve for PA:A ratio and RVSP $\geq 35 \mathrm{~mm} \mathrm{Hg}$ was not statistically significant $(0.60 ; 95 \% \mathrm{CI}, 0.48-0.73 ; p=0.10)$. Intraclass correlation coefficients were moderate for interobserver agreement in CT scan measurements of the PA:A ratio $(0.56 ; p=0.005)$.

\section{PA Diameter Measurements}

Both pPA diameter and mPA diameter were significantly associated with RVSP (both $r=0.29$ and $p=0.01$ ). In the RVSP $\geq 35 \mathrm{~mm}$ Hg group, significantly higher pPA diameters (29.5 and $27.5 \mathrm{~mm}$, respectively; $p=0.02$ ) and $\mathrm{mPA}$ diameters (29.7 and $27.6 \mathrm{~mm}$, respectively; $p=0.02$ ) were seen compared to the RVSP $<35 \mathrm{~mm} \mathrm{Hg}$ group. No significant differences in A diameter were found between both groups ( 34.7 and $33.9 \mathrm{~mm}$, respectively; $p=0.35$ ). In the RVSP $>50 \mathrm{~mm} \mathrm{Hg}$ group, only $\mathrm{mPA}$ and pPA diameters $>30 \mathrm{~mm}$ were seen, and the detection rates of patients with an elevated RVSP for various $\mathrm{pPA}$ and $\mathrm{mPA}$ diameters are shown in Table 3.

In a multiple linear regression model adjusted for age, sex, and height, both $\mathrm{mPA}$ and pPA diameters were independent predictors of the RVSP, while A diameter was not (see online suppl. Table S1; for all online suppl. material, see www.karger.com/doi/10.1159/000509719). The area under the curve for pPA diameter and RVSP $\geq 35$ $\mathrm{mm} \mathrm{Hg}$ was 0.65 (95\% CI, 0.53-0.77; $p=0.02)$ and for $\mathrm{mPA}$ diameter and RVSP $\geq 35 \mathrm{~mm} \mathrm{Hg}$ was 0.66 (95\% CI, $0.54-0.77 ; p=0.01$ ) (online suppl. Fig. S1). Intraclass correlation coefficients were good for interobserver agreement in CT-scan-measured pPA and mPA diameters (0.85 and 0.73 , respectively; both $p<0.001$ ).

\section{Discussion}

The main finding of this study is that following echocardiography, only 3 out of 255 patients (1.2\%) had an RVSP $>50 \mathrm{~mm} \mathrm{Hg}$ and 1 (0.4\%) systolic left ventricle dysfunction. This finding suggests that routinely performed echocardiography is of limited value in this cohort and highlights the need for alternative screening methods to identify at risk patients who qualify for echocardiography. In this patient group, a PA diameter $>30 \mathrm{~mm}$ could be used to select patients who qualify for echocardiography and substitute for routinely performed echocardiography in the screening for $\mathrm{PH}$.

We concluded that the prevalence of $\mathrm{PH}$ and $\mathrm{CHF}$ is low in this preselected cohort of patients with severe COPD. To our knowledge, this is the only study to evaluate the prevalence of these cardiac comorbidities in patients with COPD who qualify for bronchoscopic treatments. Right heart catheterization (RHC) is the gold standard to diagnose $\mathrm{PH}$ (defined as a mean pulmonary arterial pressure [mPAP] $>25 \mathrm{~mm} \mathrm{Hg}$ ), and echocardiography is mainly used to select patients for RHC based on the RVSP. According to guidelines, $\mathrm{PH}$ is considered unlikely in patients with an RVSP $\leq 35 \mathrm{~mm} \mathrm{Hg}$ and likely in patients with an RVSP $>50 \mathrm{~mm} \mathrm{Hg}$ [13]. Some studies have focused on the prevalence of $\mathrm{PH}$ following $\mathrm{RHC}$ in patients with severe COPD that were referred for lung volume reduction surgery or lung transplantation $[7,8$, 14]. In these studies, $\mathrm{PH}$ was found in $30-86 \%$ of the patients with advanced COPD and severe $\mathrm{PH}$ (defined as an mPAP $>35 \mathrm{~mm} \mathrm{Hg}$ ) in $4.0-9.7 \%$ of the patients, whereas only $1.2 \%$ of the screened patients needed to be excluded due to $\mathrm{PH}$ in our cohort.

The low prevalence of $\mathrm{PH}$ in our cohort could be explained by the selection of patients considered eligible for bronchoscopic treatments. In selecting patients for bronchoscopic treatments, a preselection is made of patients that are expected to encounter primarily ventilator limitations in exercise capacity based on chest CT, pulmonary function tests, and medical history. This preselection is in agreement with earlier findings that other underlying pa- 
Table 3. Detection of elevated RVSP according to CT-derived PA measurements

\begin{tabular}{|c|c|c|c|c|c|c|c|c|c|}
\hline $\mathrm{RVSP}<35 \mathrm{~mm} \mathrm{Hg}$ & $5(10.6 \%)$ & $26(55.3 \%)$ & $26(55.3 \%)$ & $21(44.7 \%)$ & $21(44.7 \%)$ & $16(34.0 \%)$ & $18(38.3 \%)$ & $12(25.5 \%)$ & $10(21.3 \%)$ \\
\hline $\mathrm{RVSP} \geq 35 \mathrm{~mm} \mathrm{Hg}$ & $4(10.3 \%)$ & $29(74.4 \%)$ & $31(79.5 \%)$ & $26(66.7 \%)$ & $27(69.2 \%)$ & $25(64.1 \%)$ & $22(56.4 \%)$ & $21(53.8 \%)$ & $14(35.9 \%)$ \\
\hline RVSP $>50 \mathrm{~mm} \mathrm{Hg}$ & $0(0 \%)$ & $3(100 \%)$ & $3(100 \%)$ & $3(100 \%)$ & $3(100 \%)$ & $3(100 \%)$ & $3(100 \%)$ & $3(100 \%)$ & $3(100 \%)$ \\
\hline
\end{tabular}

Data are presented as $n$ (\%). PA, pulmonary artery; PA:A, ratio of pulmonary artery-to-aorta diameter; mPA, main pulmonary artery diameter $(\mathrm{mm})$; pPA, perpendicular pulmonary artery diameter $(\mathrm{mm})$; RVSP, right ventricular systolic pressure.

thology is often present and underdiagnosed in patients with $\mathrm{PH}$ in COPD [15]. And most importantly, hypoxia is an important risk factor for the development of $\mathrm{PH}$ in COPD and a $\mathrm{pO} 2<6.0 \mathrm{kPa}$ is an exclusion criterion for bronchoscopic treatments [2].

Despite the preclusion of $\mathrm{PH}$ as the main aim for echocardiography, RVSP measurements could be obtained in only $33.7 \%$ of the cases. Although hyperinflation in COPD is known to impede echocardiography, other studies have reported feasible RVSP measurements in 44 and $66 \%$, respectively, of the patients with severe COPD $[5,6]$. RVSP is calculated from tricuspid regurgitation jet measurements and an estimate of the right atrial pressure. Tricuspid regurgitation has been shown to be more frequently present in increasing pulmonary artery systolic pressure (PASP), with detectable tricuspid regurgitation ranging from $10 \%$ of the patients with a PASP $<35 \mathrm{~mm}$ $\mathrm{Hg}$ up to $96 \%$ of the patients with a PASP $>50 \mathrm{~mm} \mathrm{Hg}$ [16]. Therefore, the lower percentage of successful RVSP measurements could possibly be explained by the preselection of patients with generally lower PASP. Additionally, patients in our cohort had higher mean residual volumes ( $237 \mathrm{vs.} 143 \%$ predicted), which is known to impede echocardiographic imaging [6]. Alternatively, in the earlier mentioned studies, performance of echocardiography was part of the study design. Therefore, our results may be a more appropriate reflection of successful RVSP measurements in clinical practice.

Given the limitations of echocardiography, CT-derived measurements of the $\mathrm{PA}$ have been investigated to identify patients at risk for $\mathrm{PH}$, including the PA:A ratio. A PA:A ratio $>1$ has been associated with an increased frequency of severe exacerbations in COPD [17] but has also been proposed as a screening tool for the detection of $\mathrm{PH}$ in patients with severe COPD [10].

In our study, the PA:A ratio was not a valid tool to identify patients at risk for $\mathrm{PH}$. Most importantly, all pa- tients with an RVSP $>38 \mathrm{~mm} \mathrm{Hg}$ had $\mathrm{PA}$ :A ratios $\leq 1$ in this cohort. In patients with $\mathrm{PH}$, the PA:A ratio was earlier shown to be unrelated to changes in PASP over time [18], which might suggest that an elevated PA:A ratio could be used in the phenotyping of lung diseases rather than in the detection of $\mathrm{PH}$.

Both higher mPA and pPA diameters were associated with higher RVSP in our cohort. Although statistically significant, the correlation coefficients were relatively low. This finding might be the result of both low prevalence of PH in this cohort and use of RVSP as the outcome measure. In general, RVSP is known to correlate only moderately with PASP and $\mathrm{mPAP}$ with high standard errors of the mean, $[6,19,20]$ but RVSP has been shown to be highly inaccurate in patients with advanced lung disease. Based on echocardiography, $48 \%$ of the patients with advanced lung disease were misdiagnosed with $\mathrm{PH}$, $[5,21]$ and CT-derived PA measurements have been shown to associate better with $\mathrm{mPAP}$ measurements than echocardiographic-derived estimates in patients with severe COPD [10].

In patients with severe COPD, an mPA diameter $\geq 30$ $\mathrm{mm}$ has been associated with $\mathrm{PH}[11]$. In our study, all 3 patients with an RVSP $>50 \mathrm{~mm} \mathrm{Hg}$ had $\mathrm{mPA}$ and pPA diameters $\geq 30 \mathrm{~mm}$. Since $\mathrm{mPA}$ and $\mathrm{pPA}$ diameters are strongly correlated and mPA diameter measurements are easier to perform, mPA diameter measurements are preferable to pPA diameter measurements. Therefore, we suggest using an $\mathrm{mPA}$ diameter $\geq 30 \mathrm{~mm}$ in the identification of patients at risk for $\mathrm{PH}$ in this specific patient cohort.

Our study has some limitations. Given the preselection of patients that were considered eligible for endobronchial treatment, these results are not generalizable to the entire population of patients with severe COPD. Since only 3 patients in our cohort had an RVSP $>50 \mathrm{~mm} \mathrm{Hg}$, the sample size was too small to calculate sensitivity and 
specificity for the different PA diameters. Therefore, we used the threshold of a PA diameter $\geq 30 \mathrm{~mm}$ based on an earlier study [11]. In this study, a PA diameter $\geq 30 \mathrm{~mm}$ was shown to have the highest positive and negative predictive value in the detection of $\mathrm{PH}$ in patients with severe COPD. However, patients in this study were screened for lung transplantation and might therefore not be a good reflection of our population. Furthermore, our study is limited by its retrospective design and lack of mPAP measurements. On the other hand, this study is unlikely to be repeated with RHC since the prevalence of $\mathrm{PH}$ is low in this cohort, and RHC entails considerable costs and additional risks.

In conclusion, we found that the prevalence of $\mathrm{PH}$ and CHF is low in patients selected for bronchoscopic treatments and that routinely performed echocardiography in all patients is not worthwhile. An mPA diameter $>30 \mathrm{~mm}$ followed by echocardiography could substitute for routinely performed echocardiography in all patients eligible for bronchoscopic treatments in the screening for $\mathrm{PH}$. This measurement is easy to perform and cost effective since it can be performed on the already obtained CT scans and is more patient friendly.

\section{Statement of Ethics}

We obtained written informed consent from all participants for the use of their data.

\section{Conflict of Interest Statement}

D.J.S. is an investigator, physician advisor, and consultant for PulmonX Inc. Redwood City, CA, USA. All other authors have nothing to disclose.

\section{Funding Sources}

This study was supported by the Lung Foundation Netherlands (Grant No. 5.1.17.171.0). The sponsor had no role in the design of the study, the collection and analysis of the data, or in the preparation of the manuscript.

\section{Author Contributions}

Van der Molen: contributed to the study concept and design, collected and analyzed data, and wrote the manuscript. Hartman: contributed to acquisition of data, assisted with statistical analysis, critical revision of the manuscript for intellectual content, and final approval of the submitted manuscript. Klooster: contributed to acquisition of data, critical revision of the manuscript for intellectual content, and final approval of the submitted manuscript. Kerstjens: contributed to the discussion on the results, critical revision of the manuscript for intellectual content, and final approval of the submitted manuscript. Van Melle: contributed expertise as the cardiologist involved in this study, to critical revision of the manuscript for intellectual content, and to final approval of the submitted manuscript. Willems: contributed to CT-derived measurements, critical revision of the manuscript for intellectual content, and final approval of the submitted manuscript. Slebos: contributed to the study concept and design, critical revision of the manuscript for intellectual content, and final approval of the submitted manuscript.

\section{References}

1 van Geffen WH, Slebos DJ, Herth FJ, Kemp SV, Weder W, Shah PL. Surgical and endoscopic interventions that reduce lung volume for emphysema: a systemic review and metaanalysis. Lancet Respir Med. 2019;7(4):31324.

2 Slebos DJ, Shah PL, Herth FJ, Valipour A. Endobronchial valves for endoscopic lung volume reduction: best practice recommendations from expert panel on endoscopic lung volume reduction. Respiration. 2017;93(2): $138-50$.

3 Herth FJ, Slebos DJ, Rabe KF, Shah PL. Endoscopic lung volume reduction: an expert panel recommendation. Respiration. 2016;91(3): 241-50.

4 Chen W, Thomas J, Sadatsafavi M, FitzGerald JM. Risk of cardiovascular comorbidity in patients with chronic obstructive pulmonary disease: a systematic review and meta-analysis. Lancet Respir Med. 2015;3(8):631-9.

Echocardiography in COPD Patients

Eligible for Bronchoscopic Treatments
5 Arcasoy SM, Christie JD, Ferrari VA, Sutton MS, Zisman DA, Blumenthal NP, et al. Echocardiographic assessment of pulmonary hypertension in patients with advanced lung disease. Am J Respir Crit Care Med. 2003; 167(5):735-40.

6 Laaban JP, Diebold B, Zelinski R, Lafay M, Raffoul H, Rochemaure J. Noninvasive estimation of systolic pulmonary artery pressure using doppler echocardiography in patients with chronic obstructive pulmonary disease. Chest. 1989;96(6):1258-62.

7 Thabut G, Dauriat G, Stern JB, Logeart D, Lévy A, Marrash-Chahla R, et al. Pulmonary hemodynamics in advanced COPD candidates for lung volume reduction surgery or lung transplantation. Chest. 2005;127(5): 1531-6.

8 Scharf SM, Iqbal M, Keller C, Criner G, Lee S, Fessler HE. Hemodynamic characterization of patients with severe emphysema. Am J Respir Crit Care Med. 2002;166(3):314-22.
9 Fishman A, Martinez F, Naunheim K, Piantadosi S, Wise R, Ries A, et al. A randomized trial comparing lung-volume-reduction surgery with medical therapy for severe emphysema national emphysema treatment trial research group. N Engl J Med. 2003;348(21): 2059-73

10 Iyer AS, Wells JM, Vishin S, Bhatt SP, Wille KM, Dransfield MT. CT scan-measured pulmonary artery to aorta ratio and echocardiography for detecting pulmonary hypertension in severe COPD. Chest. 2014;145(4):824-32.

11 Mohamed Hoesein FA, Besselink T, Pompe E, Oudijk EJ, de Graaf EA, Kwakkel-van Erp JM, et al. Accuracy of CT pulmonary artery diameter for pulmonary hypertension in end-stage COPD. Lung. 2016;194(5):813-9.

12 Devaraj A, Wells AU, Meister MG, Corte TJ, Wort SJ, Hansell DM. Detection of pulmonary hypertension with multidetector $\mathrm{CT}$ and echocardiography alone and in combination. Radiology. 2010;254(2):609-16. 
13 Galie N, Hoeper MM, Humbert M, Torbicki A, Vachiery J-L, Barbera JA, et al. Guidelines for the diagnosis and treatment of pulmonary hypertension: the task force for the diagnosis and treatment of pulmonary hypertension of the European Society of Cardiology (ESC) and the European Respiratory Society (ERS), endorsed by the internat. Eur Heart J. 2009; 30(20):2493-537.

14 Cuttica MJ, Kalhan R, Shlobin OA, Ahmad S, Gladwin M, MacHado RF, et al. Categorization and impact of pulmonary hypertension in patients with advanced COPD. Respir Med. 2010;104(12):1877-82.

15 Chaouat A, Bugnet AS, Kadaoui N, Schott R, Enache I, Ducoloné A, et al. Severe pulmonary hypertension and chronic obstructive pulmonary disease. Am J Respir Crit Care Med. 2005;172(2):189-94.
16 Berger M, Haimowitz A, Van Tosh A, Berdoff RL, Goldberg E. Quantitative assessment of pulmonary hypertension in patients with tricuspid regurgitation using continuous wave doppler ultrasound. J Am Coll Cardiol. 1985; 6(2):359-65.

17 Wells JM, Washko GR, Han MK, Abbas N, Nath H, Mamary AJ, et al. Pulmonary arterial enlargement and acute exacerbations of COPD. N Engl J Med. 2012;367(10):913-21.

18 Boerrigter B, Mauritz GJ, Marcus JT, Helderman F, Postmus PE, Westerhof N, et al. Progressive dilatation of the main pulmonary artery is a characteristic of pulmonary arterial hypertension and is not related to changes in pressure. Chest. 2010;138(6):1395-401.
19 Homma A, Anzueto A, Peters JI, Susanto I, Sako E, Zabalgoitia M, et al. Pulmonary artery systolic pressures estimated by echocardiogram vs cardiac catheterization in patients awaiting lung transplantation. J Heart Lung Transplant. 2001;20(8):833-9.

20 Chan KL, Currie PJ, Seward JB, Hagler DJ, Mair DD, Tajik AJ. Comparison of three doppler ultrasound methods in the prediction of pulmonary artery pressure. J Am Coll Cardiol. 1987;9(3):549-54.

21 Janda S, Shahidi N, Gin K, Swiston J. Diagnostic accuracy of echocardiography for pulmonary hypertension: a systematic review and meta-analysis. Heart. 2011;97(8):61222. 